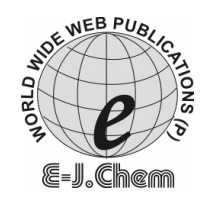

\title{
Removal of Grey BL from Dye Wastewater by Derris (Pongamia Glabra) Leaf Powder by Adsorption
}

\author{
T. MUGUGAN, A. GANAPATHI and R. VALLIAPPAN* \\ Division of Chemistry, Faculty of Engineering and Technology, \\ ${ }^{*}$ Chemistry Wing, DDE Annamalai University, Annamalai Nagar- 608 002, India. \\ arumugamganapathi@ymail.com
}

Received 16 November 2009; Accepted 10 January 2010

\begin{abstract}
The dye, Grey BL was adsorbed on an adsorbent prepared from mature leaves of the Pungan tree (Pongamia glabra). A batch adsorption study was carried out with variable adsorbate concentration, adsorbent amount and $\mathrm{pH}$. Ninety three percent of the dye could be removed by $2 \mathrm{~g}$ of the derris leaf powder from $1 \mathrm{~L}$ of an aqueous solution containing $25 \mathrm{mg}$ of the dye at $300 \mathrm{~K}$. The adsorption followed pseudo first order kinetics with a mean rate constant of $3.73 \times 10^{-3} \mathrm{~min}^{-1}$ and an intraparticle diffusion rate constant of $6.36 \times 10^{-2} \mathrm{mg}$ $\mathrm{g}^{-1} \min ^{-0.5}$. A possible mechanism of adsorption was suggested on the basis of concurrently operating surface adsorption and pore diffusion. The experimental data yielded excellent fits with Langmuir and Freundlich isotherm equations. The Langmuir monolayer capacity had a mean value of $8.27 \mathrm{mg} \mathrm{g}^{-1}$. The results indicated that the dye, Grey BL, strongly interacts with a biomass-based adsorbent, the Derris (Pongamia glabra) leaf powder.
\end{abstract}

Keywords: Grey BL, Dye adsorption, Kinetics, Dye removal, Pongamia glabra.

\section{Introduction}

The presence of dyes into streams and rivers constitutes a category of pollutants that cannot be neglected. Colour in water is aesthetically unpleasant and may contain appreciable concentration of materials with high oxygen demand and suspended solids. Many dyes and pigments have toxic as well as carcinogenic, mutagenic and teratogenic effects $^{1}$ on aquatic life and also on humans ${ }^{2}$. Dyes and pigments are widely used in textile, leather, paper, plastic and other industries. The effluents of these industries are characterized by fluctuating $\mathrm{pH}$ with large load of suspended solids and $\mathrm{COD}^{3}$. Some of the dyes and pigments present in these effluents resist biological oxidation and therefore, they require tertiary treatment ${ }^{4-6}$. 
Adsorption of dyes and pigments onto granulated activated carbon (GAC) or powdered activated carbon (PAC) is a common practice ${ }^{7-9}$. However, the technology for manufacturing good quality activated carbon is still very cost-prohibitive and the regeneration or disposal of the spent carbon is often problematic. There is also considerable loss of carbon in the waste sludge unless the adsorption is carried out through fixed process. This has prompted the use of various materials as adsorbents in order to develop cheaper alternatives by utilizing agricultural and other wastes. Such low-cost adsorbents have been investigated at the laboratory scale for the treatment of coloured effluents with different degrees of success ${ }^{3,10-20}$.

The Pungan (Derris indica (Lamk) tree (Pongamia glabra) of family Papilionaceae is native to the Indian sub-continent and its seeds and leaves have been used traditionally to treat a number of human ailments. The tree itself is known as an air purifier and different parts of the tree such as leaves, bark and seeds have been reported to possess a variety of medicinal and germicidal properties ${ }^{21}$. The oil taken from the seeds of the tree are used for anti-inflammatory treatments in the traditional system of medicine that is practiced in South India (Siddha system of medicine). The oil may also use for edible purpose. In the present work, finely ground derris leaf powder (DLP) was used as an adsorbent for dyes using aqueous Grey BL dye as a model system. The derris tree defoliates naturally during January - February each year and the leaves are collecting as a waste. The objective of the present work is to utilize the leaves as an adsorbent for dyes and pigments in water and thus, to add a scientific basis to their traditional uses.

The dye is not regarded as acutely toxic, but it can have various harmful effects. On inhalation, it can give rise to short periods of rapid or difficult breathing, while ingestion through the mouth produces a burning sensation and may cause nausea, vomiting, diarrhea, and gastritis. A large amount creates abdominal and chest pain, severe headache, profuse sweating, mental confusion, painful micturation and methemoglobinemia-like syndromes.

\section{Experimental}

Grey BL dye (Microscopic grade, Sigma-Aldrich, India) was used without further purification. All solutions were made in double distilled water. Mature derris leaves, collected from a number of derris trees, were mixed together and washed repeatedly with water to remove dust and other impurities. The leaves were dried first at room temperature in a shade and then in an air oven at 333-343 $\mathrm{K}$ for $30 \mathrm{~h}$ till the leaves could be crushed into fine powder. The powder was sieved and the 53-74 micro fractions were preserved as an adsorbent in glass bottles.

\section{Adsorption experiments}

The adsorption experiments were carried out in a batch process by using aqueous solutions of Grey BL dye. The other variable parameters were adsorbent amount, agitation time and $\mathrm{pH}$ of the medium. In each experiment, an accurately weighed amount of DLP was added to $50 \mathrm{~mL}$ of the Grey BL solution in a $100 \mathrm{~mL}$ conical flask and the mixture was agitated in a thermostatic mechanical shaker for a given length of time at a constant temperature. If necessary, the $\mathrm{pH}$ was adjusted by addition of a few drops of dilute $\mathrm{HNO}_{3}$ or $\mathrm{NaOH}$. The mixture was centrifuged (Remi Research Centrifuge) and Grey BL remaining unadsorbed $\left(\lambda_{\max }=570-580 \mathrm{~nm}\right)$ was determined spectrophotometrically (Hitachi 3210). Calibration curves are obtained with standard Grey BL solutions and the amount adsorbed was found by mass-balance procedure. 


\section{Kinetics of adsorption}

The kinetics of the adsorption processes was studied by carrying out a separate set of experiments with constant temperature, DLP amount and adsorbate concentration using the pseudo first orders Lagergren equation ${ }^{22}$. The differential rate equation is of the form:

$$
\mathrm{dq} / \mathrm{dt}=\mathrm{k}_{1}\left(\mathrm{q}_{\mathrm{e}}-\mathrm{q}_{\mathrm{t}}\right)
$$

Where $\mathrm{q}_{\mathrm{e}}$ and $\mathrm{q}_{\mathrm{t}}$ are the amount adsorbed per unit mass of the adsorbent (in $\mathrm{mg} \mathrm{g}^{-1}$ ) at equilibrium and at time $t$ and $\mathrm{k}_{1}$ is the pseudo first order rate constant $\left(\mathrm{min}^{-1}\right)$. Integrating the above equation for the boundary conditions $\mathrm{t}=0$ to $\mathrm{t}=\mathrm{t}$ and $\mathrm{q}_{\mathrm{t}}=0$ at $\mathrm{t}=0$, gives:

$$
\log \left(\mathrm{q}_{\mathrm{e}}-\mathrm{q}_{\mathrm{t}}\right)=\log \mathrm{q}_{\mathrm{e}}-\mathrm{k}_{1} \mathrm{t} /(2: 303)
$$

A linear plot of $\log \left(\mathrm{q}_{\mathrm{e}}-\mathrm{q}_{\mathrm{t}}\right) v s . \mathrm{t}$ verifies the first order kinetics with the slope yielding the value of the rate constant.

\section{Intraparticle diffusion}

The variation in the extent of adsorption with time at different initial dye concentrations was processed for evaluating the role of diffusion in the adsorption system. Adsorption is a multi-step process involving transport of the solute molecules from the aqueous phase to the surface of the solid particulates followed by diffusion into the interior of the pores. The intra-particle diffusion rate equation ${ }^{15}$ :

$$
\mathrm{q}_{\mathrm{t}}=k_{i} \mathrm{t}^{0: 5}
$$

Where $k_{i}$ is the intraparticle diffusion rate constant $\left(\mathrm{mg} \mathrm{g}^{-1} \min ^{-0.5}\right)$. The $k_{i}$ values were calculated from the slopes of the linear plots of $\mathrm{q}_{\mathrm{t}} v s . \mathrm{t}^{0.5}$.

\section{Adsorption isotherms}

The well-known Freundlich isotherm, Equation (3), is widely used to describe adsorption on a surface having heterogeneous energy distribution. The Langmuir isotherm, Equation (4) on the other hand is strictly applicable to monolayer chemisorption. The experimental data are tested with respect to both these isotherms:

$$
\begin{aligned}
& \text { Freundlich isotherm: } \mathrm{q}_{\mathrm{e}}=K_{f} C_{n} \\
& \text { Langmuir isotherm: } \mathrm{C}_{\mathrm{e}} / \mathrm{q}_{\mathrm{e}}=\left(1 / \mathrm{K}_{\mathrm{d}} \mathrm{C}_{1}\right)+\left(1 / \mathrm{C}_{1}\right) \mathrm{C}_{\mathrm{e}}
\end{aligned}
$$

Where $\mathrm{q}_{\mathrm{e}}$ is the amount of dye adsorbed at equilibrium in unit mass of DLP, $\mathrm{C}_{e}$ is the concentration of the dye in aqueous phase at equilibrium, $n$ and $\mathrm{K}_{\mathrm{f}}$ are Freundlich coefficients, $\mathrm{C}_{1}$ and $\mathrm{K}_{\mathrm{d}}$ are Langmuir coefficients. The linear Freundlich and Langmuir plots were obtained by plotting (i) $\log \mathrm{q}_{\mathrm{e}} v s . \log \mathrm{C}_{\mathrm{e}}$ and (ii) $\mathrm{C}_{\mathrm{e}} / \mathrm{q}_{\mathrm{e}} v s . \mathrm{C}_{\mathrm{e}}$ and the adsorption coefficients were computed from the slopes and the intercepts. Another important parameter, $\mathrm{R}_{\mathrm{L}}$, known as the separation factor, could be obtained from the relation:

$$
\mathrm{R}_{\mathrm{L}}=1 /\left(1+\mathrm{K}_{\mathrm{d}} \mathrm{C}_{\mathrm{ref}}\right)
$$

Where $\mathrm{C}_{\mathrm{ref}}$ is any equilibrium liquid phase concentration of the solute. It has been established $^{15}$ that (i) $0<\mathrm{R}_{\mathrm{L}}<1$ for favourable adsorption, (ii) $\mathrm{R}_{\mathrm{L}}>1$ for unfavourable adsorption, (iii) $R_{L}=1$ for linear adsorption and (iv) $R_{L}=0$ for irreversible adsorption.

\section{Results and Discussion}

\section{Kinetics of adsorption}

The kinetics of Grey BL adsorption on derris leaf powder (DLP) was studied with respect to different amounts of the adsorbent (Figure 1). 
The adsorption of dyes increased with the sorbent dosage and reached an equilibrium value after $(0.7 \mathrm{~g}$ of sorbent dosage (Figure 1$)$ As one was expected, the percentage of dye removal increased with increasing amount of biomass, however, the ratio of dye sorbed to biomass $(\mathrm{mg} / \mathrm{g}$ ) decreased with the increasing amount of biomass (Figure 2). The interactions appeared to attain equilibrium rapidly after about $1 \mathrm{~h}$ of agitation. Assuming pseudo first order kinetics for the adsorption process, $\log \left(\mathrm{q}_{\mathrm{e}}-\mathrm{q}_{\mathrm{t}}\right)$ was plotted against $\mathrm{t}$ and the linearity of the Langmuir plots (Figure 2) confirmed the same (the correlation coefficients for the plots were in the range $0.92-0.99$ ). The first order rate constants evaluated from these plots were between $2.99 \times 10^{-3}$ and $5.07 \times 10^{-3} \mathrm{~min}^{-1}$ for different amounts of the adsorbent.

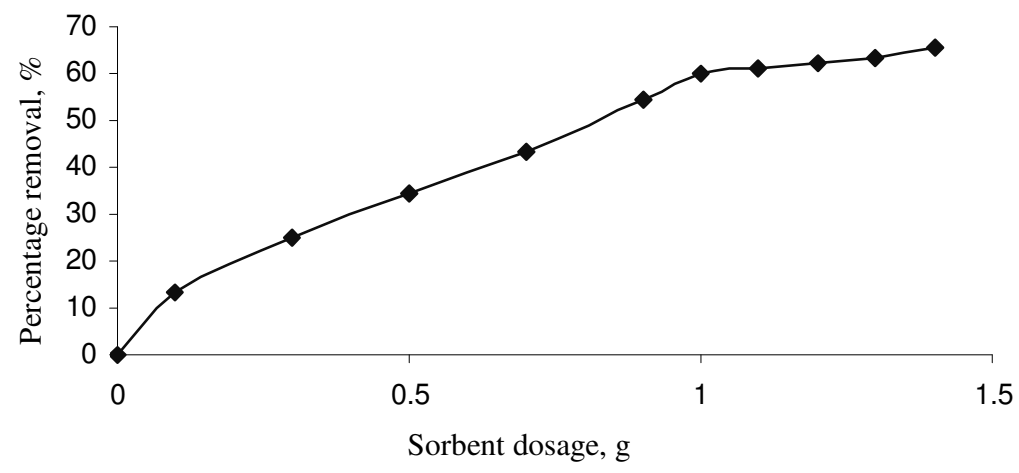

Figure 1. Effect of adsorption (\%) of the dye Grey BL on different amounts of the adsorbent, Derris leaf powder at $300 \mathrm{~K}$ (dye concentration $100 \mathrm{mg} / \mathrm{L}$ )

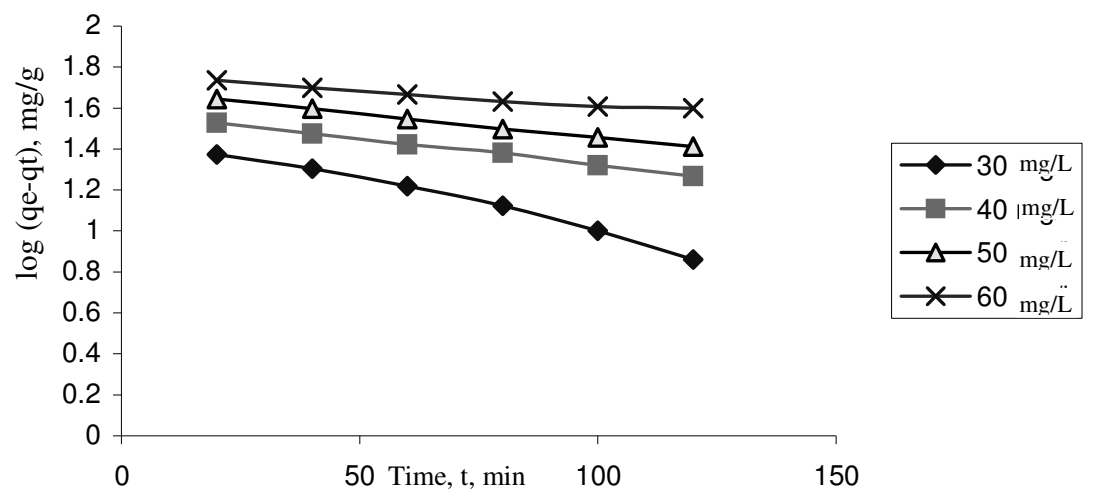

Figure 2. Lagergren plots for adsorption of Grey BL on derris leaf powder at $300 \mathrm{~K}$ (dye concentration $50 \mathrm{mg} / \mathrm{L}$ )

The dye-DLP interactions could thus be predicted as reasonably fast. It may be noted that the pseudo first order reaction differs from a true first order reaction in two aspects: the expression $\mathrm{k}_{1}\left(\mathrm{q}_{\mathrm{e}}-\mathrm{q}_{\mathrm{t}}\right)$ does not represent the number of available sites and the parameter $\log \mathrm{q}_{\mathrm{e}}$ is an adjustable parameter whose value is not equal to the intercept of the plot of $\log \left(\mathrm{q}_{\mathrm{e}}-\mathrm{q}_{\mathrm{t}}\right) v s . \mathrm{t}^{15}$. In the present work, the intercepts of the Langmuir plots were very close to the theoretical log $\mathrm{q}_{\mathrm{e}}$ values and therefore, the kinetics of Grey BL Blue adsorption on Derris leaf powder could be considered as almost true first order in nature. Further, the difficulty usually associated with the application of the pseudo first order model to an adsorption system arising from the uncertainty of finding reliable $\mathrm{q}_{\mathrm{e}}$ values within a reasonable time was not applicable in the present work as the system was very close to equilibrium even after $1 \mathrm{~h}$ of agitation time. 
A number of authors have reported pseudo first order kinetics for adsorption of dyes on various adsorbents prepared from biological sources similar to the Derris leaf powder. The values of the rate constant, $\mathrm{k}_{1}$, obtained by these workers are compared with the values obtained in the present work in Table 1 (conditions vary). It is to be noted that the first order rate constant for the interaction of Grey BL with Derris leaf powder, $\mathrm{k}_{1}$, in the present work were 10-100 times less when compared to the values obtained for adsorption of Methylene Blue on water hyacinth roots $\left(4.2 \times 10^{-2}-6.9 \times 10^{-2} \mathrm{~min}^{-1}\right)^{24}$, on banana peel $\left(3.5 \times 10^{-1} \mathrm{~min}^{-1}\right)$ and orange peel $\left(2.9 \times 10^{-1} \mathrm{~min}^{-1}\right)^{25}$.

Table 1. Pseudo first order rate constant data for adsorption of dyes on various adsorbents

\begin{tabular}{lllc}
\hline \multicolumn{1}{c}{ Adsorbent } & \multicolumn{1}{c}{ Dyes } & \multicolumn{1}{c}{$\mathrm{k}, \mathrm{min}^{-1}$} & Reference \\
\hline Banana pith & Acid Violet & $(1.8-13.0) \times 10^{-2}$ & {$[32]$} \\
Orange peel & Rhodamine B & $(2.3-9.95) \times 10^{-1}$ & {$[13]$} \\
Water hyacinth & Methylene Blue & $(4.2-6.9) \times 10^{-2}$ & {$[28]$} \\
Orange peel & Congo Red & $(3.6-4.9) \times 10^{-2}$ & {$[13]$} \\
Procion Orange & & $(8.3-15.5) \times 10^{-2}$ & {$[13]$} \\
Rhodamine-B & & $(9.9-29.9) \times 10^{-2}$ & {$[13]$} \\
Pith Basic Red 22 & & $(1.0-1.1) \times 10^{-2}$ & {$[33]$} \\
Acid Red 114 & & $(8.9-9.5) \times 10^{-3}$ & {$[4]$} \\
Orange peel & Acid Violet 17 & $(3.5-6.9) \times 10^{-2}$ & {$[3]$} \\
Banana peel & Methyl Orange & $3.9 \times 10^{-1}$ & {$[25]$} \\
Methylene Blue & & $3.5 \times 10^{-1}$ & {$[25]$} \\
Rhodamine B & & $1.9 \times 10^{-1}$ & {$[25]$} \\
Orange peel & Methyl Orange & $4.0 \times 10^{-1}$ & {$[25]$} \\
Methylene Blue & & $2.9 \times 10^{-1}$ & {$[25]$} \\
Rhodamine B & & $2.1 \times 10^{-1}$ & {$[25]$} \\
Coir pith & Congo Red & $(2.1-3.9) \times 10^{-1}$ & {$[31]$} \\
Neem leaf powder & Brilliant Green & $7.32 \times 10^{-3}$ & {$[29]$} \\
Neem leaf powder & Methylene Blue & $(2.9-5.1) \times 10^{-3}$ & {$[34]$} \\
\hline
\end{tabular}

\section{Intraparticle diffusion}

The plots of $\mathrm{q}_{\mathrm{t}} v s . \mathrm{t}^{0.5}$ (Figure 3) were found to be linear with regression coefficients of 0.90-0.99. The intra-particle diffusion rate constant, $\mathrm{k}_{\mathrm{i}}$, was in the range of $(1.21-14.17) \times 10^{-2} \mathrm{mg} \mathrm{g}^{-1} \mathrm{~min}^{-0.5}$. The linearity of the plots demonstrated that intra-particle diffusion played a significant role ${ }^{25}$ in the uptake of the dye by Derris leaf powder. This also confirms that adsorption of the dye on the adsorbent was a multi-step process, involving adsorption on the external surface and diffusion into the interior. All the steps slow down as the system approaches equilibrium. If the steps are independent of one another, the plot of $\mathrm{q}_{\mathrm{t}} v s . \mathrm{t}^{0.5}$ usually shows two or more intersecting lines depending on the exact mechanism, the first one of these lines representing surface adsorption and the second one intra-particle diffusion. The absence of such features in the plots of the present work indicated that the steps were indistinguishable from one another and that the intraparticle diffusion was a prominent process right from the beginning of dye-solid interaction. Weber and Morris ${ }^{26}$ have proposed that if the uptake of the adsorbate varies with the square root of time, intra-particle diffusion can be taken as the rate-limiting step. $\mathrm{H}_{\mathrm{o}}{ }^{27}$ has shown that it is essential for the $\mathrm{q}_{\mathrm{t}} v s . \mathrm{t}^{0.5}$ plots to go through the origin if the intra-particle diffusion is the sole rate limiting step. Since this was also not the case in the present work (the $\mathrm{q}_{\mathrm{t}} v \boldsymbol{s}$. $\mathrm{t}^{0.5}$ plots have intercepts in the range $4.50-20.40 \mathrm{mg} \mathrm{g}^{-1}$ ), it may be concluded that surface adsorption and intra-particle diffusion were concurrently operating during the Grey BL - DLP interactions. 


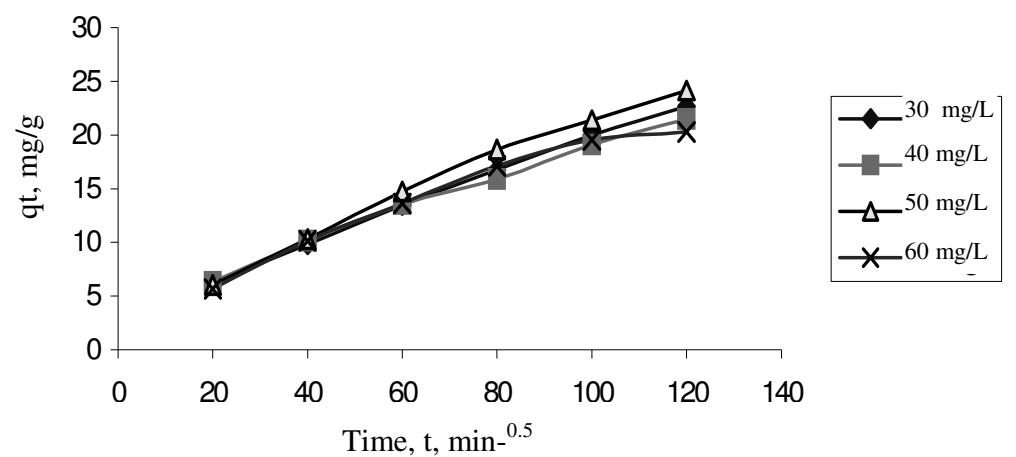

Figure 3. Plots of $\mathrm{q}_{\mathrm{t}}\left(\mathrm{mg} \mathrm{g}^{-1}\right)$ vs. $\mathrm{t}^{0.5}$ for evaluating intra-particle diffusion rate constant (Grey BL concentration $40 \mathrm{mg} / \mathrm{L}$, temperature $300 \mathrm{~K}$ )

\section{Effect of the amount of adsorbent and the initial concentration of the adsorbate}

To investigate the effect of adsorbent mass on amount of adsorption, a series of experiments were carried out keeping the agitation time constant and varying both the amount of adsorbent and the adsorbate concentration at constant temperature. For a Derris leaf powder of $50 \mathrm{mg} / \mathrm{L}$, the amount adsorbed $3.60 \mathrm{mg} \mathrm{g}^{-1}$. The Grey BL concentration was increased from 50 to $250 \mathrm{mg} / \mathrm{L}$ (Table 2). The results as a whole indicate two distinct trends: the amount adsorbed, $\mathrm{q}_{\mathrm{t}}\left(\mathrm{mg} \mathrm{g}^{-1}\right)$, increased with an increase in the dye concentration and decreased with an increase in the amount of the adsorbent. The latter trend may be due to the effect of adsorbent mass on porosity of the adsorbent suspension. In general, the trends might have been influenced by changes in a number of physical properties of the solid-liquid suspensions including their viscosity.

Table 2. Amount of Grey BL adsorbed on Derris leaf powder at $300 \mathrm{~K} \mathrm{in} \mathrm{mg} \mathrm{g}^{-1}$

\begin{tabular}{cccc}
\hline $\begin{array}{c}\text { Dye concentration } \\
\mathrm{mg} / \mathrm{L}\end{array}$ & $\begin{array}{c}\text { Weight of } \\
\text { Biomass } \mathrm{mg}\end{array}$ & $\begin{array}{c}\text { Amount adsorbed } \\
\mathrm{mg} \mathrm{g}^{-1} \text { for DLP }\end{array}$ & $\begin{array}{c}\text { Amount of dye } \\
\text { adsorbed, \% }\end{array}$ \\
\hline 15 & 50 & 3.60 & 11.40 \\
30 & 100 & 4.50 & 25.50 \\
50 & 150 & 5.52 & 44.48 \\
70 & 200 & 6.27 & 63.73 \\
90 & 250 & 7.00 & 83.00 \\
\hline
\end{tabular}

\section{Effect of $p H$}

Contact time $5 \mathrm{~h}$

An important influencing factor for dye biosorption on agricultural by-products has been referred to $\mathrm{pH}$ as in most studies published in the literature. The variation of equilibrium dye uptake with initial $\mathrm{pH}$ is given in Figure 4 for an initial dye concentration of $100 \mathrm{mg}^{-1}$ at $300 \mathrm{~K}$ for a contact time of $4 \mathrm{~h}$. As seen from the Figure 4, the biosorption with $\mathrm{pH}$ of the medium varying from 2.0 to 9.0 , the adsorption of the dye oscillated between 60 and $70 \%$. Ho et al. ${ }^{28}$ have shown that the extent of removal of a basic dye (Basic Red 18) by activated clay decreased rapidly as $\mathrm{pH}$ increased from 3.0 to 5.0 and from 8.0 to 10.0. However, the adsorption remained constant within the range of $\mathrm{pH}$ 5.0-8.0. It was suggested that the increase in sorption depended on the properties of the adsorbent surface and the dye structure. At a lower $\mathrm{pH}$, the adsorbent surface might have become negatively charged attracting more of the basic dye molecules. It is likely that positive charge develops on the 
surface of an adsorbent in acidic medium, resulting in a higher adsorption of anionic dyes than in a basic solution. If this is the case, the sorption of the cationic dye should decrease at a lower $\mathrm{pH}$. In addition, the effect of $\mathrm{pH}$ may also be explained on the basis of surface hydroxylation, acid-base dissociation and surface complex formation.

The adsorption of Grey BL increases with the increase of $\mathrm{pH}$ of the solution. The variation in the amount of adsorbed dye with respect to $\mathrm{pH}$ of the medium has been shown in Figure 4. The maximum removal was noted at $\mathrm{pH} 6.5-7.5$. With an increase of $\mathrm{pH}$ from 4.2 to 7.02 , the uptake of Grey BL increases from 52 to $63 \%$ which is close to the satisfactory level by Derris leaf powder at a temperature $300 \mathrm{~K}$.

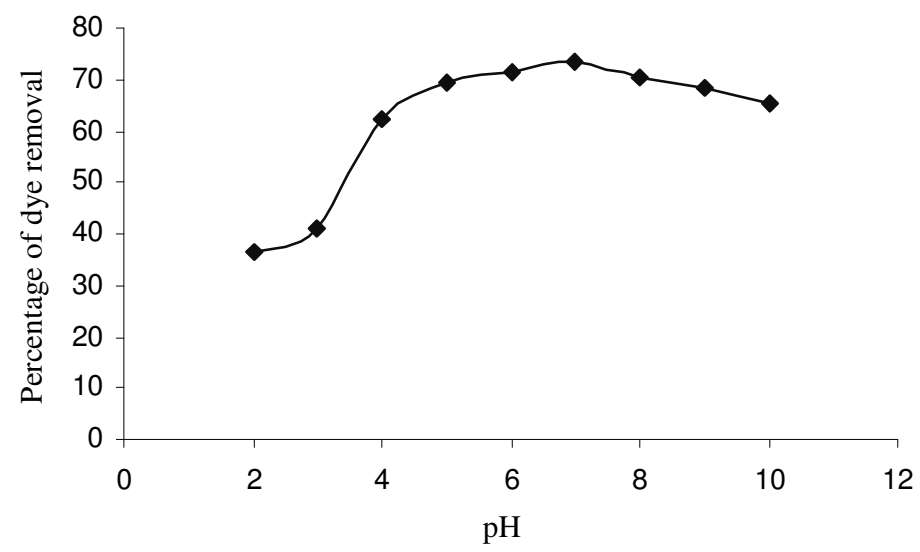

Figure 4. Effect of $\mathrm{pH}$ on the removal of Grey BL by Derris leaves powder (concentration $40 \mathrm{mg} / \mathrm{L}$ temperature $300 \mathrm{~K}$.

\section{Adsorption isotherms}

The experimental data yielded good linear plots with both Freundlich isotherm (Figure 5, Regression coefficient R -0.99) and Langmuir isotherm (Figure 6, R: 0.96-0.99). The Freundlich coefficient, $n$, which should have values in the range of $0<n<1$ for favourable adsorption, remained in a narrow range of $0.51-0.66$ for different amounts of the adsorbent. The Freundlich adsorption capacity, $\mathrm{K}_{\mathrm{f}}$, was in the range of 2.42-9.47 $\mathrm{L} \mathrm{g}^{-1}$.

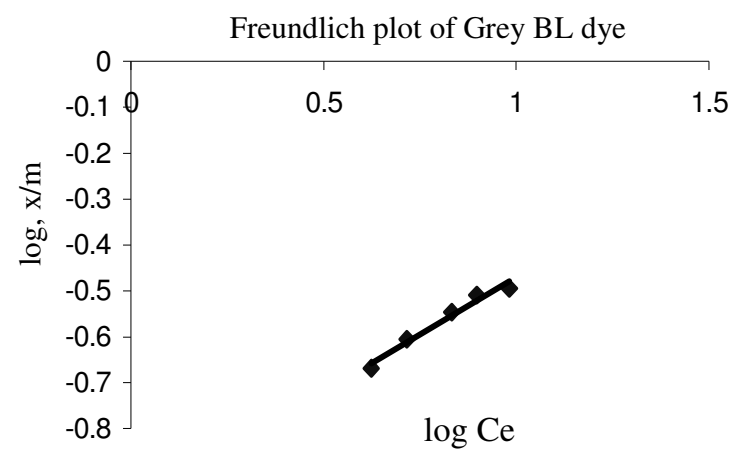

$\bullet$ Pungai

Figure 5. Freundlich isotherms for adsorption of Grey BL on Derris leaf powder at $300 \mathrm{~K}$ with dye concentration of $50 \mathrm{mg} / \mathrm{L}$ and agitation time $5 \mathrm{~h}$ 


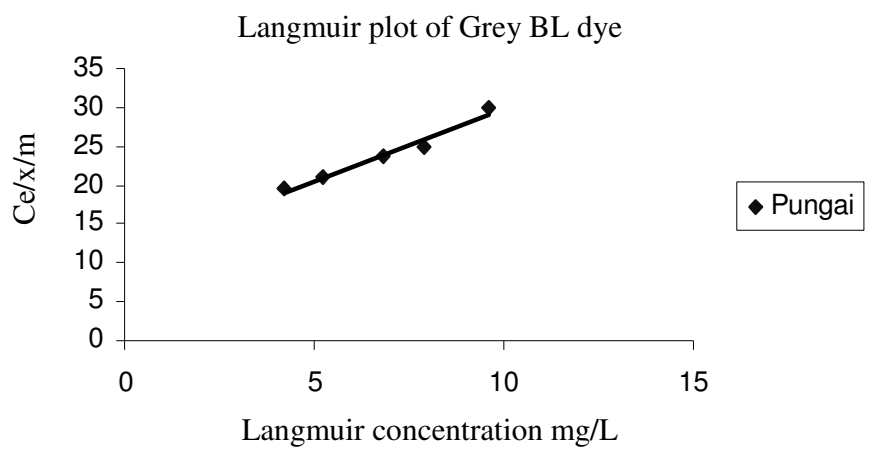

Figure 6. Langmuir isotherms for adsorption of Grey BL on Derris leaf powder at $300 \mathrm{~K}$ with dye concentration of $50 \mathrm{mg} / \mathrm{L}$ and agitation time $5 \mathrm{~h}$

The Langmuir monolayer adsorption capacity, $\mathrm{C}_{1}$, was large with values between 4.26 and $11.32 \mathrm{mg} \mathrm{g}^{-1}$. The Langmuir adsorption intensity, $\mathrm{K}_{\mathrm{d}}$, had values of $0.186-0.729 \mathrm{~L} \mathrm{mg}^{-1}$. The dimensionless separation factor, $\mathrm{R}_{\mathrm{L}}$, had an average value of 0.96 in the range of 0.91-0.98 in concurrence with the suggested values for favourable adsorption. This value being very close to 1.0 , the adsorption of the dye on DLP could be described as linear in nature, i.e., there was an almost linear increase in adsorption with increase in DLP amount. The isotherm constants indicated that the Derris leaf powder had very good potential as an adsorbent for the dye, Grey BL and it might have similar potential for other dyes, as had already been demonstrated for Brilliant Green (Bhattacharya) ${ }^{29}$.

The Langmuir monolayer capacity of the Derris leaf powder $\left(4.26-11.32 \mathrm{~g} \mathrm{~kg}^{-1}\right.$, may be compared with a number of adsorbents derived from biological sources like the Derris leaf powder. Some of the large adsorption capacities recorded were: $160 \mathrm{~g} \mathrm{~kg}^{-1}$ for Atrazon Blue on Maize $\mathrm{cob}^{30}, 94.5 \mathrm{~g} \mathrm{~kg}^{-1}$ for Maxilon Red also on Maize $\mathrm{cob}^{30}$ and $133.7 \mathrm{~g} \mathrm{~kg}^{-1}$ for Brilliant Green on Neem leaf powder ${ }^{29}$. The Derris leaf powder thus has good potential to be used as an adsorbent for the removal of Grey BL from water.

\section{Conclusion}

The results of this work can be summarized as follows:

(i) Derris leaf powder is a promising adsorbent for removal of the dye Grey BL from water. A small amount $(2 \mathrm{~g} / \mathrm{L})$ of the adsorbent could almost completely decolorize an aqueous solution of Grey BL (40 mg/L) if agitated for $5 \mathrm{~h}$.

(ii) The experimental data produced perfect fit with the Freundlich isotherm showing that the surface of the DLP particles was heterogeneous, non-specific and non-uniform in nature. The mechanism of the dye-DLP interactions is thus likely to be very complicated involving a wide range of sites differing in a number of aspects including energy considerations.

(iii) The data were in good agreement with the Langmuir isotherm.

(iv) The adsorption of the dye on DLP followed pseudo first order kinetics with the interactions largely over within the first hour.

The Derris tree regularly sheds its leaves during January-February, which become waste. These leaves can be put to good use as an adsorbent for removal of colour from industrial and other effluents. However, as with all other bio-resources, the processes are likely to be very complicated and a detailed characterization of the surface will be necessary to develop more insight into the mode of action. 


\section{Acknowledgment}

The authors are grateful to the Professor and Head of the Department of Chemistry and the authorities of the Annamalai University for providing necessary facilities to complete this work.

\section{References}

1. McKay G, Otterburn M S and Aga J A, Water Air Soil Pollut., 1985, 24, 307-322.

2. Gregory A R, Elliot S and Kluge P, J Appl Toxicol., 1991, 1, 308-313.

3. Sivraj R, Namasivayam C and Kadirvelu K, Waste Management, 2001, 21, 105-10.

4. An H, Yi Q, Xiasheng G and Tang W Z, Chemosphere, 1996, 33, 2533-2542.

5. Liakou S, Pavlou S and Lyberatos G, Water Sci Technol., 1997, 35(4), 279-286.

6. Sarasa J, Roche M P, Ormad M P, Gimeno E, Puig A and Ovelleiro J L, Water Res., 1998, 32, 2721-2727.

7. Walker G M and Weatherley L R, Water Res., 1997, 31, 2093-2101.

8. Walker G M and Weatherley L R, Environ Pollut., 1998, 99, 133-136.

9. Chern Jia-Ming and Wu Chia-Yuan, Water Res., 2001, 35, 4159-4165.

10. Nawar S S and Doma H S, Sci Total Environ., 1989, 79, 271-279.

11. Pollard S J T, Fowler G D, Sollars C J and Perry R, Sci Total Environ., 1992, 116, 3331-3352.

12. Nassar M M, Hamoda M F and Radwan G H, Water Sci Technol., 1995, 32, 27-32.

13. Namasivayam C, Muniasamy N, Gayatri K, Rani M and Ranganathan K, Bioresour Technol., 1996, 57, 37-43.

14. Ramakrishna K R and Viraraghavan T, Water Sci Technol., 1997, 36, 189-196.

15. Ho Y S and McKay G, Chem Eng J., 1998, 70, 115-124.

16. McKay G, Porter J F and Prasad G R, Water Air Soil Pollut., 1999, 114, 423-438.

17. Grini G, Bioresource Technol., 2006, 97, 1061-1085.

18. Forgacs E and Gserhati G Oros, Environ Int., 2004. 30, 953-971.

19. Pearce C 1, Lloyd J R and Guthri J T, Dyes and Pigments, 2003, 58, 179-196.

20. Azza Khaled, Ahmed El Nemr, Amany El-Sikaily and Ola Abdelwahab, Desalination, 2009, 238, 210-232.

21. Chopra R N, Nayer S L and Chopra I C. Glossary of Indian medicinal plants. New Delhi: CSIR; 1956, 31.

22. Hall K R, Eagleton L C, Acrivos A and Vermeulen T Ind Eng Chem Fund., 1966, 5(2), 212-223.

23. Khan S A, Rehman R and Khan M A, Waste Manag, 1995, 15, 271-282.

24. Low K S, Lee C K and Tan K K, Bioresour Technol., 1995, 52, 79-83.

25. Gurusamy Annadurai, Juang Ruey-shin and Lee Duu-Jong, J Hazard Mater., 2002, B92, 263-274.

26. Weber W J and Morris J C, J Sanit Eng Div Am Soc Civ Eng., 1963, 89, 31-60.

27. Ho Y S, Water Res., 2003, 37(10), 2323-30.

28. Ho Y S, Chiang Chun-Chiao and Hsu Yung-Chien, Separat Sci Technol., 2001, 36, 2473-2488.

29. Bhattacharyya K G and Sarma A, Dyes Pigments, 2003, 57, 211-222.

30. El-Geundi M S, Water Res., 1991, 25, 271-273.

31. Namasivayam C and Kavitha D, Dyes Pigments, 2002, 54, 47-58.

32. Namasivayam C and Kanchana N, Chemosphere, 1992, 25, 1691-1705.

33. Ho Y S and McKay G, Resour Conserv Recycling, 1999, 25, 171-193.

34. Krishna G Bhattacharyya and Arunima Sharma, Dyes and Pigments, 2005, 165, 51-59. 


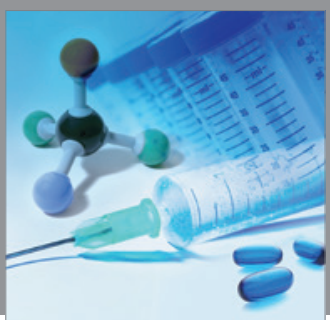

International Journal of

Medicinal Chemistry

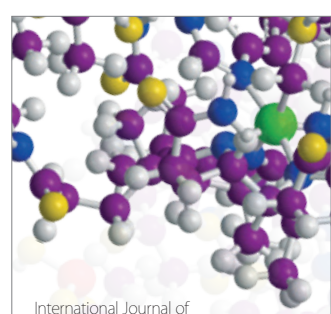

Carbohydrate Chemistry

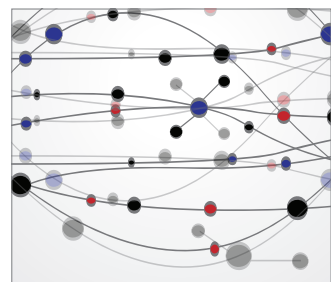

The Scientific World Journal
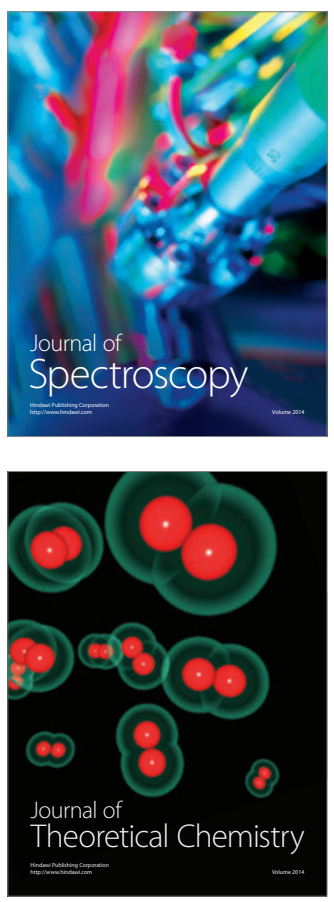
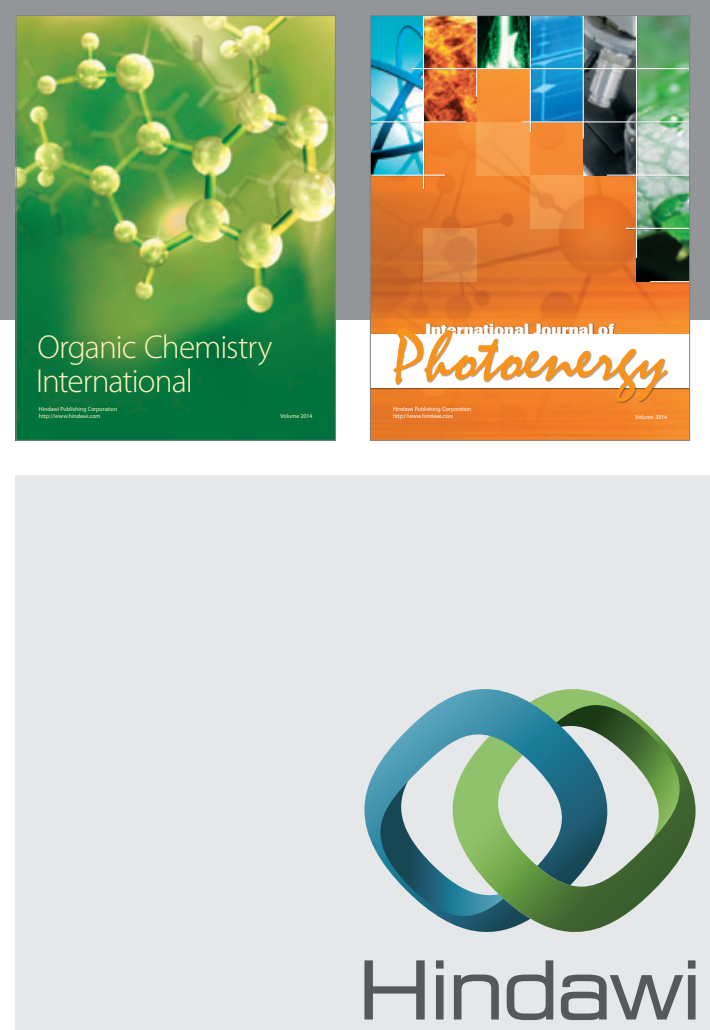

Submit your manuscripts at

http://www.hindawi.com
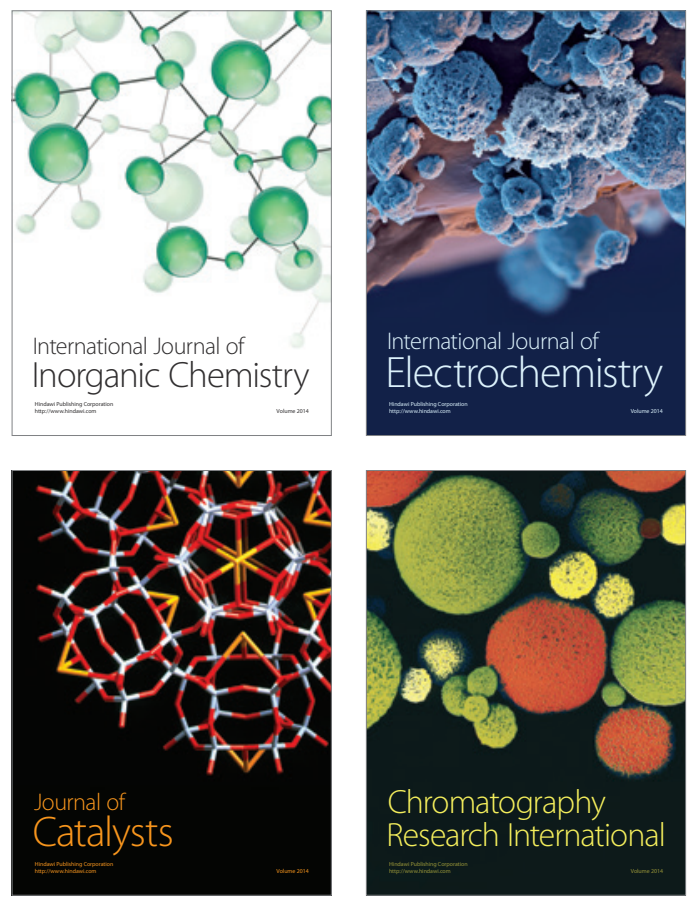
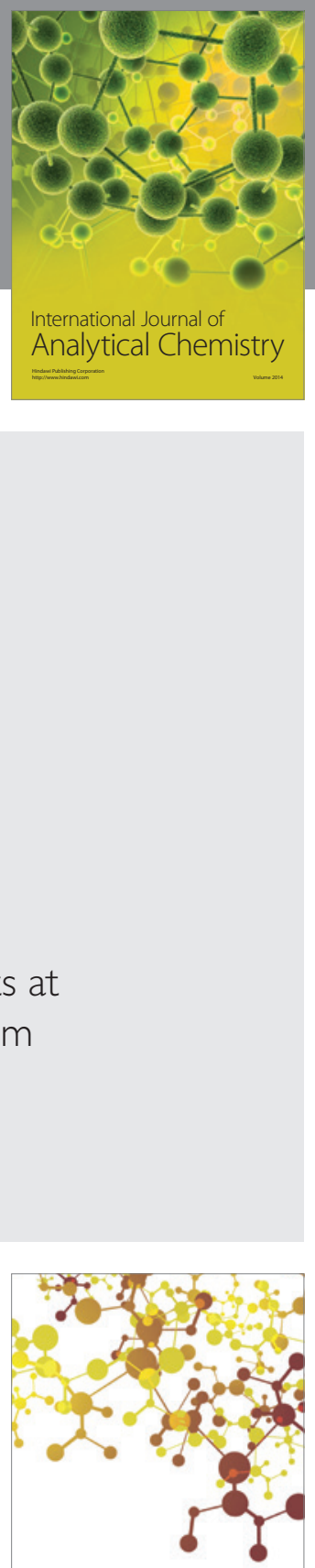

Journal of

Applied Chemistry
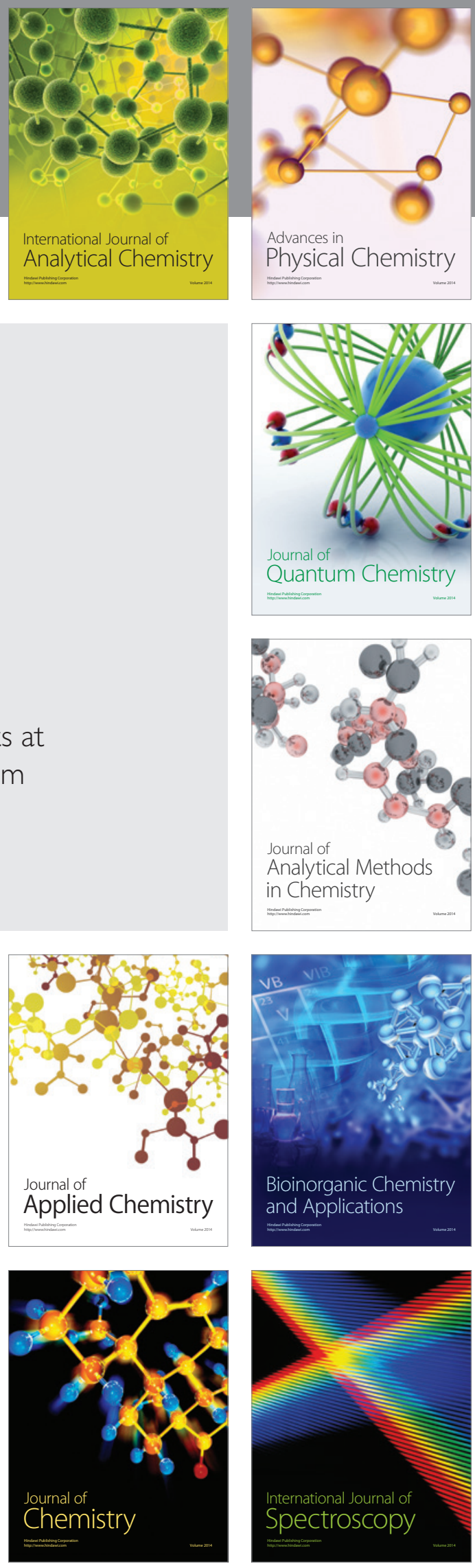